\title{
Tuning hierarchical architecture of 3D polymeric scaffolds for cardiac tissue engineering
}

\section{E. Traversa , B. Mecheri , C. Mandoli , S. Soliman , A. Rinaldi , S. Licoccia , G.} Forte , F. Pagliari , S. Pagliari , F. Carotenuto, M. Minieri \& P. Di Nardo

To cite this article: E. Traversa , B. Mecheri , C. Mandoli , S. Soliman , A. Rinaldi , S. Licoccia , G. Forte , F. Pagliari , S. Pagliari , F. Carotenuto , M. Minieri \& P. Di Nardo (2008) Tuning hierarchical architecture of 3D polymeric scaffolds for cardiac tissue engineering, Journal of Experimental Nanoscience, 3:2, 97-110, DOI: 10.1080/17458080701713946

To link to this article: https://doi.org/10.1080/17458080701713946

册 Published online: 13 Aug 2008.

Submit your article to this journal $\widetilde{1}$

Џلll Article views: 126

Q View related articles ¿

4 Citing articles: 13 View citing articles 준 


\title{
Tuning hierarchical architecture of 3D polymeric scaffolds for cardiac tissue engineering
}

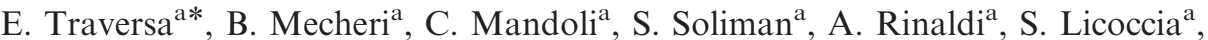

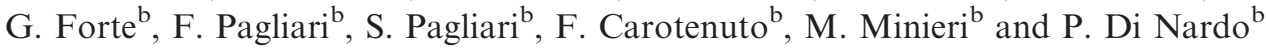 \\ ${ }^{a}$ Department of Chemical Science and Technology, University of Rome "Tor Vergata", Rome; \\ ${ }^{b}$ Department of Internal Medicine, University of Rome "Tor Vergata", Rome
}

(Received 1 August 2007; final version received 29 September 2007)

Tissue engineering combines the fields of engineering, chemistry, biology, and medicine to fabricate replacement tissues able to restore, maintain, or improve structurally and functionally damaged organs. The approach of regenerative medicine is of paramount importance for treating patients with severe cardiac diseases. For successful exploitation, the challenge for cardiac regenerative medicine is to identify the suitable combination between the best cell source for cardiac repair and the design of the optimal scaffold as a template for tissue replacement. Adult stem cells have the potential to improve regenerative medicine with their peculiar feature to self-renew and differentiate into various phenotypes. Insights into the stem cell field lead to the identification of the suitable scaffold features that enhance the ex vivo proliferation and differentiation of stem cells. Scaffolds composed of natural and/or synthetic polymers can organise stem cells into complex architectures that mimic native tissues. To achieve this, a proper design of the chemical, mechanical, and morphological characteristics of the scaffold at different length scales is needed to reproduce the tissue complexity at the cell-scaffold interface. Hierarchical porosities are needed in a single construct, at the millimetre scale to help nutrition and vascularisation, at the micrometer scale to accommodate cells, and at the nanometre scale to favour the expression of extra-cellular matrix components. The present study has been undertaken to setup strategies to integrate stem cells and tailored scaffolds, as a tool to control cardiac tissue regeneration. Among the many available techniques for scaffold fabrication, porogen leaching, phase separation, and electrospinning were selected as low-cost and user-friendly technologies to fabricate tuneable, hierarchically porous matrices that mimic aspects of the cell native surroundings. The biological validation of these scaffolds was performed by implanting adult stem cells.

Keywords: tissue engineering; scaffold; stem cells; microstructure; hierarchical porosity

*Corresponding author. Email: traversa@uniroma2.it 


\section{Introduction}

Tissue engineering emerged in the early 1990s to address limitations of organ trasplantation and synthetic tissue replacements, focusing on the transplant of a biofactor within a biocompatible matrix known as a scaffold [1]. Since then, some clinical success has been obtained for hard tissues, such as bones [2] and cartilages [3], and for bidimensional soft tissues, such as cornea [4] and skin [5], while the reconstruction of more complicated soft tissues is far more challenging.

Cardiovascular diseases are the main cause of death in the western world. New solutions are needed to regenerate hearts damaged by myocardial infarction and to address the shortage of heart donors. Cardiac tissue engineering approaches are mainly based on the use of 3D biocompatible, bioerodable scaffolds and cardiac cells to reconstitute contractile cardiac muscle-like tissues in vitro that might be utilised for the replacement of diseased myocardium in vivo [6,7]. Another approach is the superposition of bidimensional layers prepared using cell sheet engineering [8]. In this context, it becomes crucial to identify a suitable cell source. The main limitation of cardiac tissue engineering is the inability of cardiac myocytes to proliferate [9]. Recent advances in stem cell research now offer a promising cell source for the treatment of heart failure, due to their ability to self-renew and their potential to differentiate into the specialised cells [10,11].

The identification of the proper source of cells is not sufficient for the success of the tissue reconstruction. A suitable interfacing between cells and scaffold is necessary for maintaining the activity of functional cells, regulating cell behavior, and reconstructing three-dimensional (3D) tissues. The scaffold should exhibit biocompatibility and biodegradability [12], high porosity and adequate pore size to favour cell attachment and growth, as well as to facilitate the diffusion of nutrients to and waste products from the implant [13]. The mechanical properties of the scaffold are also a further key factor to fit to provide the correct stress environment for the neotissues [14].

Various materials have been explored as tissue engineering scaffolds, including natural compounds, such as collagen, hyaluronate, alginate, chitosan, as well as synthetic polymers such as polycaprolactone (PC), polyglicolide (PGA), polylactide (PLA), and their copolymers [15].

The selection of the scaffold material is a part of the proper design of the scaffold chemical, mechanical, and morphological characteristics at different length scales, needed to reproduce the tissue complexity at the cell-scaffold interface. Figure 1 shows the features of a cardiac tissue at different length scales: (i) an optical micrograph of a heart tissue section showing that vascular ducts have size at the millimetre scale, (ii) a scanning electron (SEM) micrograph of cardiac stem cells showing that their size is of about $20 \mu \mathrm{m}$ [16], and (iii) a scheme of the extracellular matrix (ECM) components at the nanometre scale. Remarkably, an increasing nanoscale roughness of the scaffold walls has been found to increase cell attachment, proliferation, and expression of ECM components [17]. The scaffold should incorporate in a single construct the information that can trigger the reproduction of the cardiac tissue with all the different features. Therefore, approaches in scaffold design must be able to create hierarchical porosities in a single construct, at the millimetre scale to help nutrition and vascularisation, at the micrometer scale to accommodate cells, and at the nanometre scale to favour the expression of extra-cellular matrix components, with the desired chemical and mechanical functions. In our view nanoscale porosity can be regarded as a patterning 


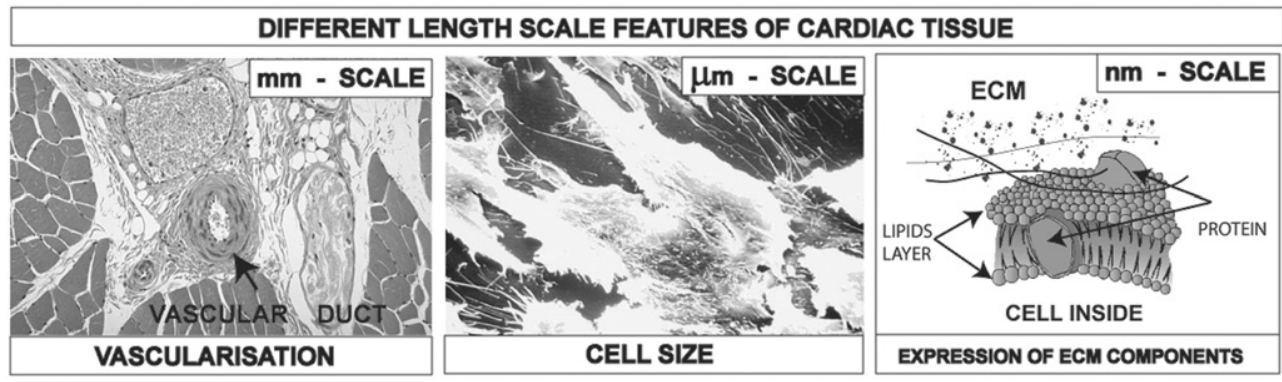

Figure 1. Different length scales of cardiac tissue to be integrated into the scaffold: $\mathrm{mm}$ scale for vascularisation and nutrition, $\mu \mathrm{m}$ scale for cell accomodation, $\mathrm{nm}$ scale for the expression of ECM components.

technique to induce and tune the nanoscale roughness for the purpose of controlling ECM expression. Furthermore, by a chemical standpoint, it also brings in the possibility to store growth factors for cell differentiation. The importance of producing three-dimensional structures with porosities at scales from the nanometre to millimetre level has been reported mainly for osteoblasts, to influence the interaction between cells ad scaffold in terms of mass-transport requirements for cell nutrition, migration and attachment [17]. In some cases the emphasis has been put onto the nanoscale features needed by the scaffold, again in most of the cases for bone treatments $[18,19]$. However, the important issue is the challenge to integrate hierarchical porosities in a single construct. Although there are certainly similarities amongst the various cells, there are also specificities for the different tissues, and what is valid for bones should be critically evaluated for heart, which is the purpose of the present study.

Several processing techniques have been developed over the past two decades to cast a large variety of materials into scaffolds suitable for the many different applications of tissue engineering and cell types (e.g. soft vs. hard tissues). Our strategy for the fabrication of $3 \mathrm{D}$ scaffolds endowed with hierarchical porosities was the development of low-cost techniques enabling scaffold tailoring. Three low-cost techniques have been investigated, namely porogen leaching, phase separation and electrospinning.

Noteworthily, none of them has emerged universally yet as the superior choice over the others, being all three currently active research topics [20-22]. The basic principles of each of these techniques have been known for some time, but the leading theme of our discourse is the possibility to opportunely tune these technologies to fabricate matrices with controlled architecture and tuneable morphological features, to match the requirements of hierarchical porosity and roughness that mimic the cell native surroundings.

The biological validation of the prepared constructs was made by implanting adult stem cells, namely murine bone marrow-derived mesenchymal stem cells (mMSC) [23].

\section{Scaffold fabrication techniques}

\subsection{Porogen leaching techniques}

Porogen leaching techniques [24] involves the use of suitable porogens to be introduced into the polymer matrix and subsequently removed to generate porosity within the 
scaffold itself. The size and shape of the pores are entirely determined and tailored by those of the porogen chosen.

In this work paraffin micro spheres and sodium chloride $(\mathrm{NaCl})$ grains were selected as porogen agents. While $\mathrm{NaCl}$ is readily available commercially, paraffin was produced in-house by melting pure paraffin pellets into an aqueous solution kept at around $80^{\circ} \mathrm{C}$ in the presence of $5 \mathrm{wt} \%$ of a surfactant, namely Pluronic $147^{\circledR}$, or gelatin. The solution was kept stirring vigorously for about $1 \mathrm{~h}$ and instantly frozen by adding ice-cold water, in order to solidify paraffin micro spherical drops. This procedure allowed to obtain a very broad dispersion of micro particle diameters. Sieving the particles can readily yield a monodisperse population in terms of porogen size. The porogen particles were then poured and pressed into a mould, then kept at $30^{\circ} \mathrm{C}$ so that partial merging of the particles could be achieved. A PLA/chloroform solution was cast on the mould to fill the interspaces between the porogen particles. After the evaporation of the solvent, the scaffold was washed with a suitable agent being solvent for the porogen and non-solvent for the polymer, i.e., hexane for paraffin removal and hot water for salt removal, respectively.

Figure 2 shows the typical SEM micrographs of the porous PLA scaffold obtained by the porogen leaching technique. Regarding $\mathrm{NaCl}$ as porogen (Figure 2(a)), cubic porosity can be obtained, with the size being controlled by the porogen dimensions. The inset shows a magnified detail of the leaching pathways suggesting that, although the salt leached out, the resulting network of pores might be rather occluded and, hence, difficult to access for the cells. Size and shape of the porogen agent determine the degree of percolation of the porosity. Spherical porosity in a close packed arrangement can be obtained by using paraffin as porogen agent (Figure 2(b)). In this case the cross-sectional view (see inset in Figure 2(b)) shows spherical open structure and then communication paths between each sphere.

The porogen leaching technique is easy to carry out. The opportune selection and preparation of the porogen as well as the balance of the polymer/porogen ratio allowed us to obtain controlled scaffolds in terms of porosity and pore shape and size. However, the control of features at millimetre scale is less easy.

\subsection{Phase separation technique}

The phase separation technique is based on thermodynamic demixing of a homogeneous polymer-solvent solution into a polymer-rich phase and a polymer-poor phase.

Phase separation techniques, especially thermally induced phase separation (TIPS) coupled with freeze-drying, have been widely used for the preparation of porous membranes for filtration and separation, as well as for scaffold fabrication [25-27)]. These techniques, generally time and energy consuming, lead to the formation of highly porous membranes.

The procedure that we adopted consisted in a solid-liquid extraction of the solvent from a polymer-solvent frozen solution, the solvent acting as a porogen agent. Briefly, PLLA (5 wt.\%) was dissolved in dioxane and the solution was cast in a Petri dish and frozen at $-18^{\circ} \mathrm{C}$. The solvent was removed by immersing the frozen polymer solution in a pre-cooled $\left(-18^{\circ} \mathrm{C}\right)$ aqueous ethanol solution $(80 \mathrm{wt} . \%)$ overnight. Several temperatures for the aqueous ethanol bath were explored, ranging from $-18^{\circ} \mathrm{C}$ to room temperature. 
(a)
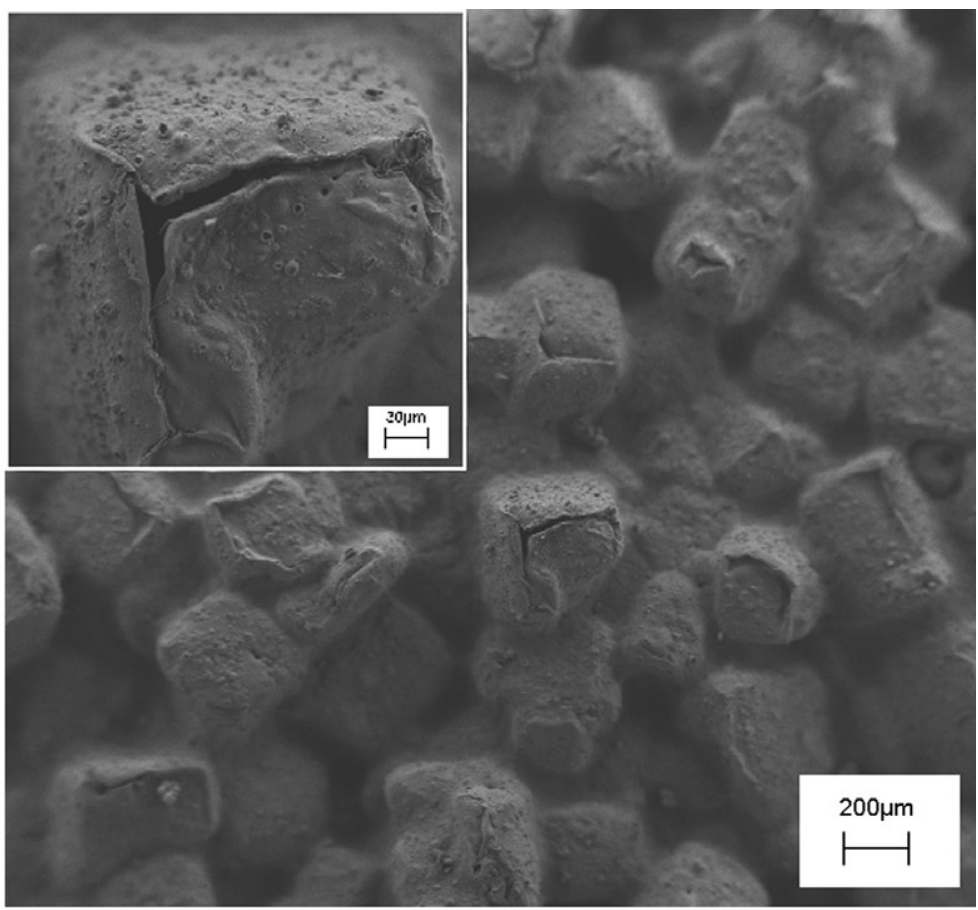

(b)
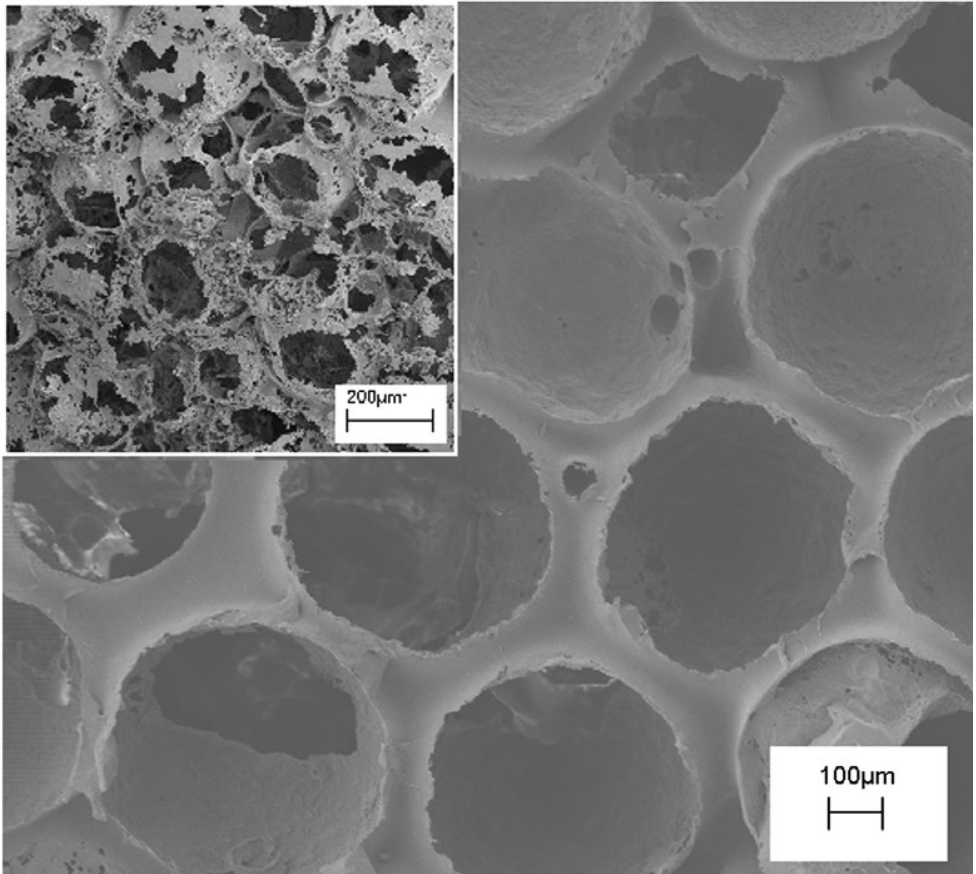

Figure 2. SEM micrographs of PLA scaffolds prepared by: (a) $\mathrm{NaCl}$ leaching technique, the inset reports a zoomed area of the scaffold; (b) paraffin leaching techniques, the inset reports the cross-sectional view. 
The solvent was extracted out and replaced with ethanol aqueous solution that was removed by drying the scaffold under vacuum for 5 hours at room temperature.

This resulted in a low-cost and fast procedure that allowed to remove easily any trace of solvent by using a non-cytotoxic environment [28].

Figures 3(a) and (b) show the comparison between the morphology of PLA scaffolds obtained by the solid-liquid extraction technique performed in isothermal $\left(T_{1}=-18^{\circ} \mathrm{C}\right)$ and non-isothermal $\left(-18^{\circ} \mathrm{C}<T_{2}<25^{\circ} \mathrm{C}\right)$ conditions, respectively. Both samples put in evidence a regular, homogeneous, and highly porous surface, the pore size being different depending on the preparation conditions. In particular, the cellular structures obtained at $T_{1}$ (Figure 3(a)) showed a smaller pore size than the sample prepared in non-isothermal conditions (Figure 3(b)). Further details are highlighted in the insets of Figure 3 that shows zoomed areas of the scaffold surface. The inset in Figure 3(a) shows that the PLA scaffold prepared in isothermal conditions $\left(T_{1}\right)$ exhibited pores of about $20 \mu \mathrm{m}$ in diameter, being the porosity partially occluded. The inset in Figure 3(b) shows that the PLA scaffold prepared in non-isothermal conditions $\left(T_{2}\right)$ exhibited larger porosity, being the pore size larger than the pores of the PLA scaffold prepared at $T_{1}$. In both cases, pores at the nanometre scale can be observed in the polymeric foam struts.

It is evident that by tuning the parameters governing the preparation process (i.e., temperature), different scaffolds can be obtained, in terms of morphology and porosity. It is known that the pore size requirements are strongly dependent on the specific tissue engineering application, according to the given cell size, the pore size generally ranging from 5 to over $400 \mu \mathrm{m}$ [29].

By using this method, the thermodynamics and the kinetics of the process of solvent extraction/replacing can be controlled to obtain a scaffold with specific requirements in terms of pore size and therefore in terms of structure-properties relationship, not limited to cardiac tissues.

\subsection{Electrospinning technique}

Electrospinning is a polymer processing technique that has been revitalised with the advent of tissue engineering. The working principle of the technique consists of applying a highvoltage electric field (of the order of $1 / 10 \mathrm{kV}$ ) between a metallic capillary containing a desired polymeric solution/melt and a collecting electrode (usually a conductive plate) electrically grounded. When the electrical field overcomes the resistance of the surface tension of the polymeric solution, the electrically charged solution is ejected from the capillary towards the counter electrode. The polymeric jet stretches under the action of the electrostatic force and produces long and thin fibers [30]. In practice, the polymer solution is electrospun from a flat-ended needle of a syringe, whose shaft is actuated by a programmable syringe pump that supplies the solution to the needle and fuels the process. The possibility to fabricate highly interconnected porous polymeric network, makes electrospinning an attractive technology for drug delivery applications, which is another major endeavour of this technique besides biomedical substrates for cell transplants [31]. Electrospinning is also suitable to fabricate hybrid or ceramic fibers [32].

In most of the cases reported in the literature, electrospinning is used to prepare mats of fibers to be used as scaffolds for tissue engineering, with limited control in porosity and 
(a)

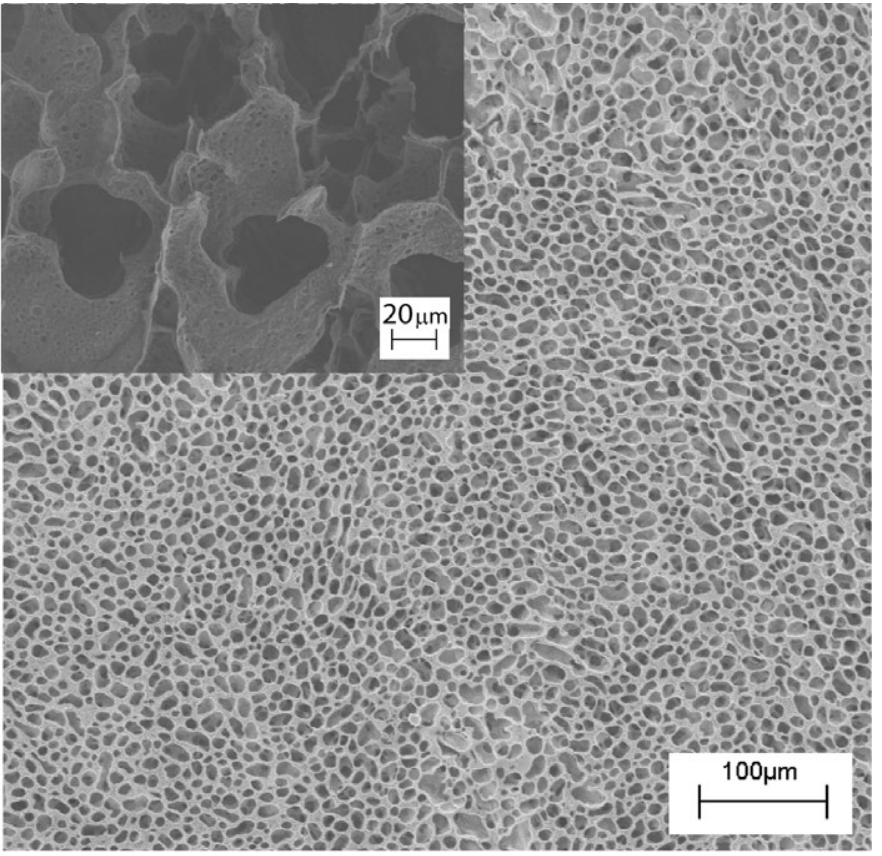

(b)

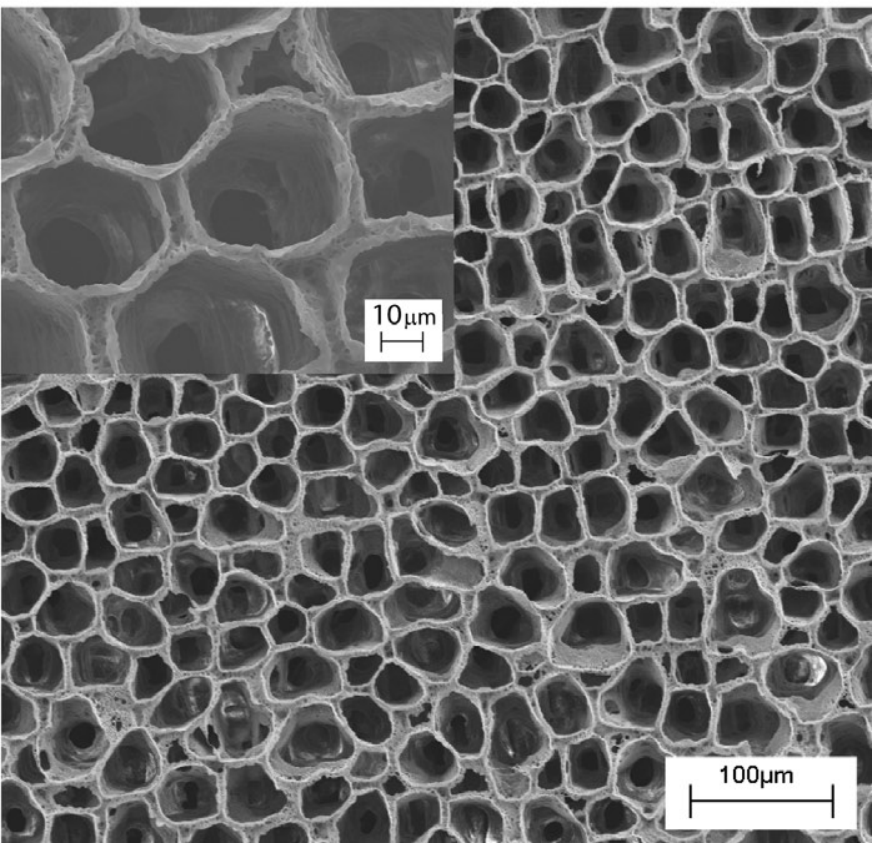

Figure 3. SEM images of a PLA scaffold prepared by the phase separation technique at two different temperature ( $T$ ) of solvent extraction, (a) $T=-18^{\circ} \mathrm{C}$ and (b) $-18^{\circ} \mathrm{C}<T<25^{\circ} \mathrm{C}$. The insets show high magnification SEM micrographs of a PLA scaffold prepared by the phase separation technique at two different temperature $(T)$ of solvent extraction, (a) $T_{1}=-18^{\circ} \mathrm{C}$ and (b) $-18^{\circ} \mathrm{C}<T_{2}<25^{\circ} \mathrm{C}$. 
therefore in cell adhesion and growth [33]. Our purpose was to highlight the tunability of most geometrical and morphological properties on the entire hierarchy of scales of the scaffolds using electrospinning. Thus, besides controlling the fibre diameter, it is possible for example to modify the macro porosity by changing the confluence, the number of layers, or the alignment of the fibres in the network. Besides the macroporosity, micro/nanoporosity may also exist and can be controlled. Figure 4 shows electrospun PLLA nanofibers $(300 / 400 \mathrm{~nm}$ in diameter) with characteristic nanopores, whose size can be controlled via process parameters (i.e., applied voltage, electrode distance and configuration, concentration and viscosity of the solution, solution flow rate, etc). As a consequence of the opportunity to integrate different length scales in a single structure, electrospun scaffolds appear to mimic the architecture of the natural extracellular matrix (ECM) better than the counterparts from other techniques [34,35]. Natural ECM consists of proteoglycans matrix embedding fibrous collagens organised in a three-dimensional porous network with fibres arranged in hierarchical structures from nanometer length scale fibrils to macroscopic tissue architecture [36]. Similarly, electrospun scaffolds are inherently multiscale structures with nano- or micro fibres with macro scale interconnected pores.

Electrospinning allows also the control of fibre alignment for the purpose of tuning the macro texturing of the scaffold. In general, if a simple collecting plate (e.g. an aluminium foil) is used, the electrospun fibres deposit randomly, forming a spaghetti-like stack. Our goal, instead, was to control the fibre alignment through the usage of patterned electrodes. Amongst other reasons, this is relevant for tailoring mechanical properties and large porosity. As a first step, the formation of a bundle made of quasi-parallel fibres was investigated. Figure 5(a) shows the experimental setup used, where two $\mathrm{Cu}$ parallel bars were used as grounded collecting electrodes. Each bar was $50 \mathrm{~mm}$ long, with a square cross section $5 \mathrm{~mm}$ wide. They were placed $50 \mathrm{~mm}$ apart at a distance of about $170 \mathrm{~mm}$ from the syringe needle charged at about $20 \mathrm{kV}$. An auxiliary $180 \mathrm{~mm}$ diameter $\mathrm{Cu}$ ring was also

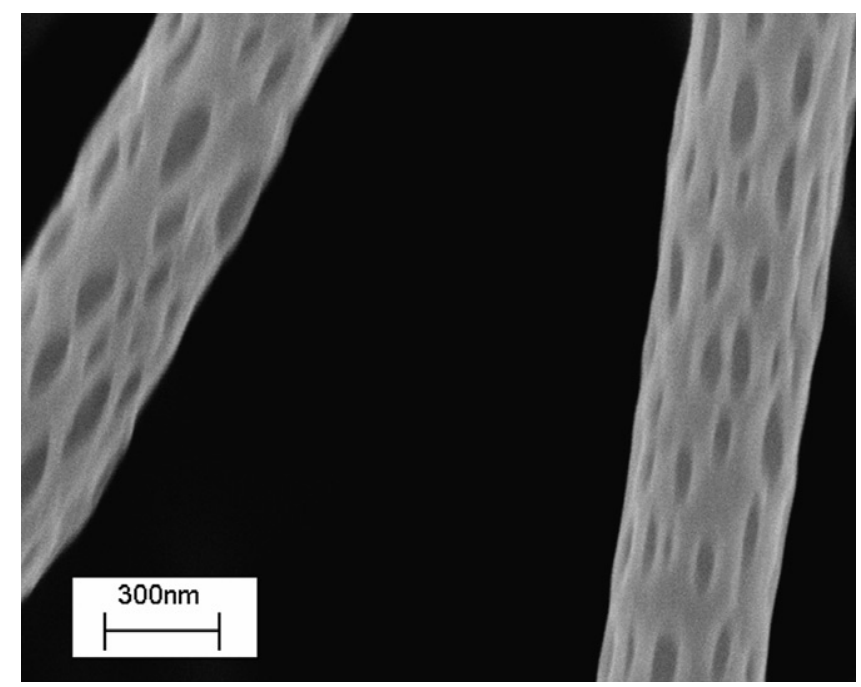

Figure 4. SEM image of PLA electrospun nanofibers with nanopores. 
connected to the generator and placed right below the needle in order to stabilise the electric field around the fibre and control the jet motion [37]. In this configuration, when a 10 wt. \% poly(1-caprolactone) (PCL) in a solution of chloroform-methanol (7:1) was used, fibers with a diameter of $2 / 4 \mu \mathrm{m}$ electrospun orderly between the $\mathrm{Cu}$ bars, rendering the highly oriented bundle shown in Figure 6(a). This result is relevant per se but, more importantly, may serve as a building block to device scaffold with more complicated patterns. As a proof of concept application, another experiment was performed using the same experimental set-up with the sole addition of another pair of $\mathrm{Cu}$ bar electrodes placed at $90^{\circ}$ from the former, as shown in Figure 5(b). The aim was the fabrication

(a)

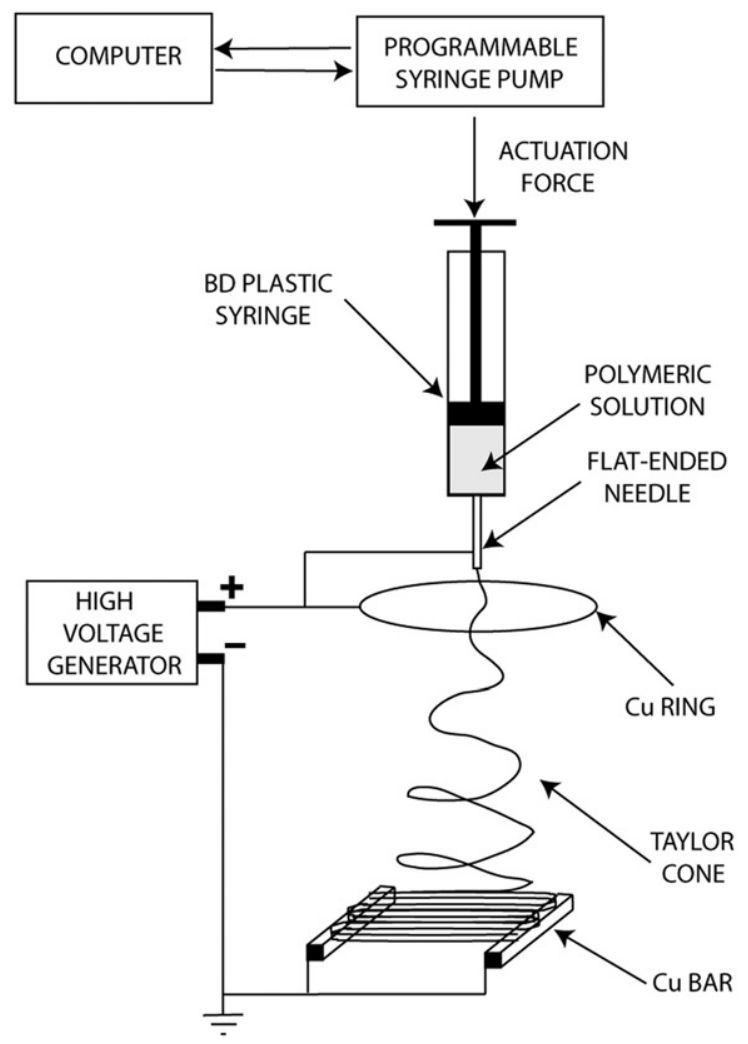

(b) ORTHOGONAL PAIRS OF GROUNDED PAIRS OF CU BAR
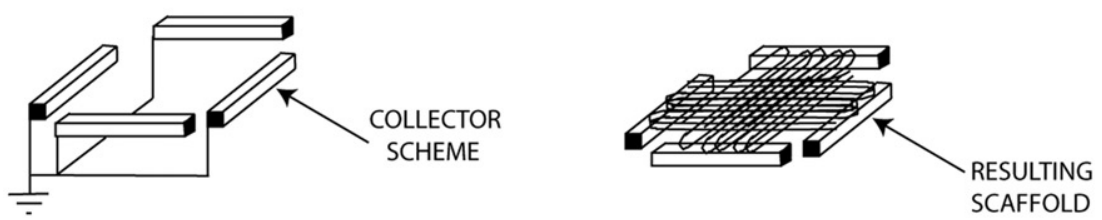

Figure 5. Schematics of the electrospinning experimental set up, where the grounded collecting electrodes were (a) two $\mathrm{Cu}$ parallel bars, (b) two pairs of $\mathrm{Cu}$ bar electrodes placed orthogonal to each other. 
(a)

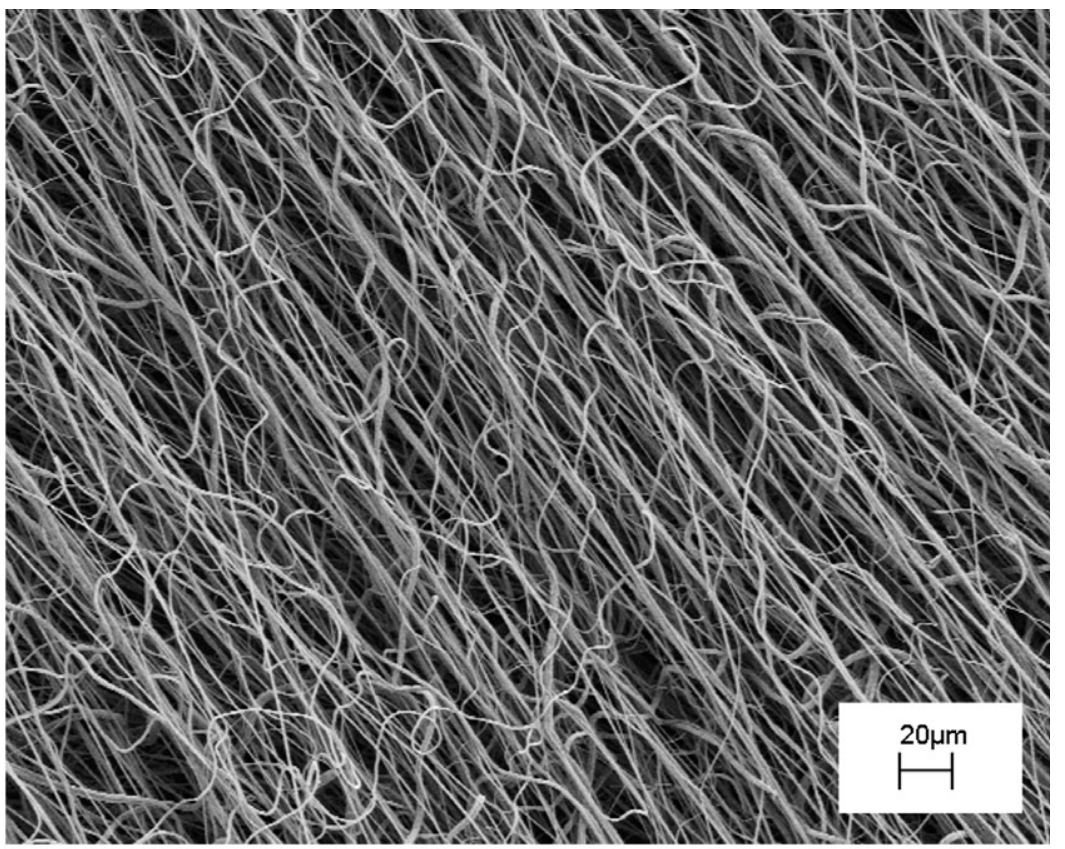

(b)

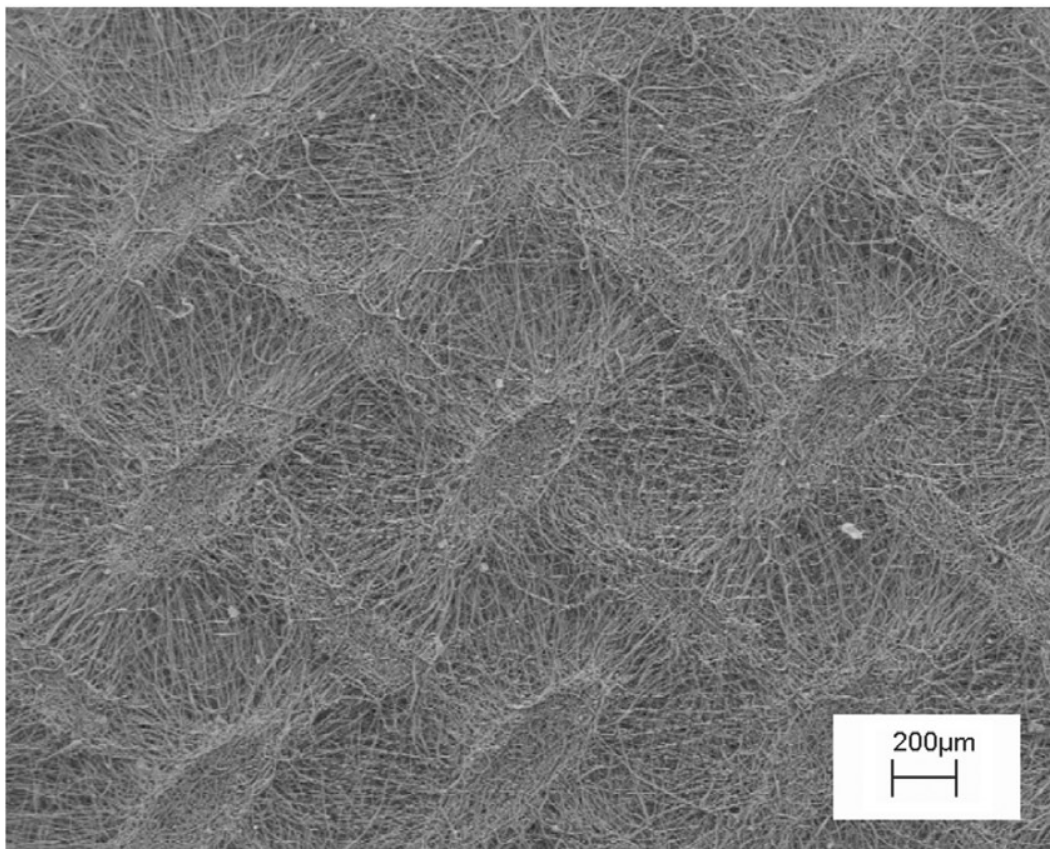

Figure 6. SEM micrographs of (a) oriented PCL fiber bundle, (b) macroscopically textured PCL scaffold. 
(a)

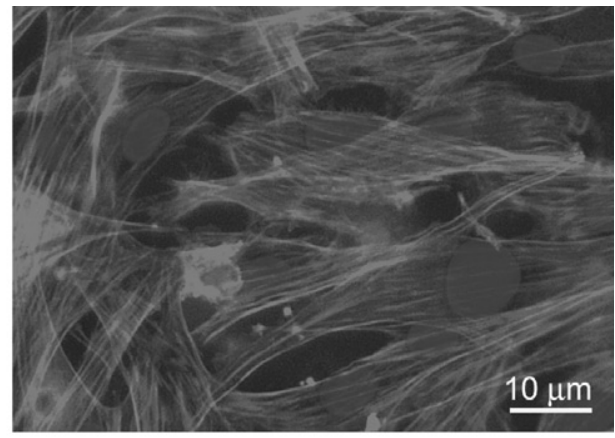

(b)

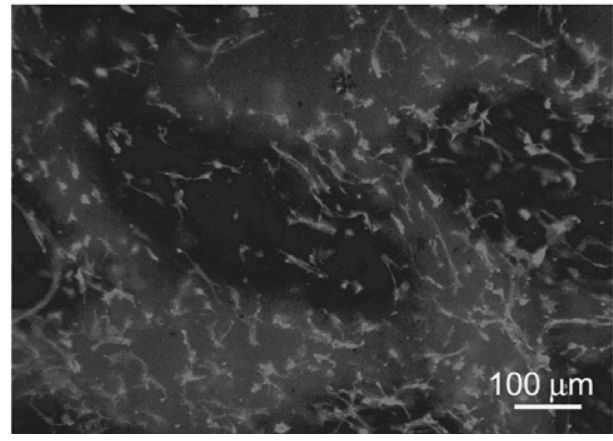

Figure 7. Immunofluorescence analysis of F-actin expression (red) in mMSC grown after $72 \mathrm{~h}$, on (a) PLA scaffold shown in Figure 3(b), (b) PCL scaffold shown in Figure 6(b). Nuclei were stained with 4',6'-diamidino-2-phenylindole (DAPI). Images of cell samples were taken with a Leica DMRB microscope using a digital camera. The images were representative of at least five random fields for each sample.

of a scaffold made with two groups of fibres oriented along orthogonal directions. Figure 6(b) shows that the resulting scaffold exhibited indeed a macroscopic texture with a short-range ordered plot with periodic features orthogonal to each other.

This approach for electrospinning appears to be a viable technique to modulate the in-plane elasticity of the scaffold. In fact, in a previous work [23] it has been demonstrated that cardiac progenitor cells differentiate into cardiac phenotype and align along the direction where the elastic properties of the scaffold matched the elastic properties of the cardiac cells.

\section{Biological validation of scaffolds}

The biological validation of the produced scaffolds was performed in vitro using a murine Lineage negative, Sca-1 positive, mesenchymal stem cell line of bone marrow origin (mMSC). Cells were seeded on sterilised and equilibrated scaffolds at the concentration of $3 \times 10^{4} / \mathrm{cm}^{2}$. Cell viability and proliferation were tested after 24,48 , and 72 hours. Cell viability was assessed by trypan blue staining. Data showed that no significant evidence of cell death was found with respect to cells grown on chamber slides in standard culture 
conditions (used as controls). To detect the proliferation ability, cycling cells were calculated as the ratio between the number of mitotic nuclei and total number of nuclei fixed and stained with DAPI (4',6'-diamidino-2-phenylindole, Sigma-Aldrich, Milan, Italy) by fluorescence microscope analysis. Data showed that mitotic nuclei number of cells grown on scaffolds increased of 1.5 fold, after $24 \mathrm{~h}$ and 3 folds, after $48 \mathrm{~h}$, similarly to controls. After $72 \mathrm{~h}$, no significant number of mitotic nuclei was observed, being cells grown at confluence. The validation was successful for all the scaffolds discussed inhere. For illustrative purpose, Figure 7 shows the immunofluorescence (IF) images of the mMSC seeded on scaffolds shown in Figures 3(b) and 6(b), respectively. Stem cells were able to colonise the pores created and to adhere functionally to the scaffolds. Indeed adherent cells, decorated with tetra-rhodamine conjugated phalloydine, directed against F-actin, showed a typical elongated shape and well organised stress fibres (Figure 7(a)). Cells with elongated shapes are also visible in Figure 7(b), grown on the electrospun scaffold. In this case the cells appeared to concentrate more in regions with higher density of fibres (which correspond to the brighter spots of the background due to autofluorescence of the polymer). In summary, the results demonstrated not only the cytocompatibility of the materials used, but also significant adhesion and proliferation of seeded cells onto the constructs.

\section{Conclusions}

The body of the experimental results demonstrated that 3D multiscale polymeric scaffolds for tissue engineering can be pursued with several approaches, each one having a characteristic signature.

Porogen leaching (in a lesser extent), phase separation, and electrospinning techniques, all allowed the fabrication of porous scaffolds exhibiting features on different length scales, whose properties can be finely tuned by controlling the process parameters. Changing the size and shape of a target porogen, as well as modifying the temperature profile of a phase separation process, is a low-cost and user-friendly operation, enabling scaffold architecture in a broad range of length scales.

Similarly, changing the materials (e.g., polymer, solvent, the composition of the solution) and/or the experimental setup (e.g., applied voltage, electrode distance, electrode pattering) can radically transform the appearance of the fibre network prepared using electrospinning. We demonstrated that, by means of purposely designed collecting electrodes, it is possible to switch from a totally random macrotexture to an ordered arrangement, consisting either of a quasi-parallel fibre bundle or a quasi-woven network from two such bundles in the cases examined inhere.

In summary, the fabrication of tuneable scaffolds with hierarchical porosities, made of biodegradable polymers, was demonstrated for cardiac tissue engineering. Adult stem cells adhered and proliferated onto the fabricated constructs, demonstrating the cytocompatibility of the materials used.

\section{Acknowledgements}

The technical support of Cadia D'Ottavi is gratefully acknowledged. The authors wish to thank Dr. Elisabetta Di Bartolomeo for helpful discussions. 


\section{References}

[1] R. Langer and J.P. Vacanti, Tissue engineering, Science 260 (1993), p. 920.

[2] H. Petite, V. Viateau, W. Bensaïd, A. Meunier, C. de Pollak, M. Bourguignon, K. Oudina, L. Sedel, and G. Guillemin, Tissue-engineered bone regeneration, Nature Biotechnol. 18 (2000), p. 959.

[3] Y. Cao, J.P. Vacanti, K.T. Paige, J. Upton, and C.A. Vacanti, Transplantation of chondrocytes utilising a polymer-cell construct to produce tissue engineered cartilage in the shape of a human ear, Plast. Reconstruct. Surg. 100 (1997), p. 297.

[4] K. Nishida, M. Yamato, Y. Hayashida, K. Watanabe, K. Yamamoto, E. Adachi, S. Nagai, A. Kikuchi, N. Maeda, H. Watanabe et al., Corneal reconstruction with tissue-engineered cell sheets composed of autologous oral mucosal epithelium, N. Eng. J. Med. 351 (2004), p. 12.

[5] M.N. Banta and R.S. Kirsner, Modulating diseased skin with tissue engineering: actinic purpura treated with Apligraf ${ }^{\circledR}$, Dermatol. Surg. 28 (2002), p. 1103.

[6] R.L. Carrier, M. Papadaki, M. Rupnick, F.J. Schoen, N. Bursac, R. Langer, L.E. Freed, and G. Vunjak-Novakovic, Cardiac tissue engineering: cell seeding, cultivation parameters, and tissue construct characterization, Biotech. Bioeng. 64 (1999), p. 580.

[7] W.H. Zimmermann, C. Fink, D. Kralisch, U. Remmers, J. Weil, and T. Eschenhagen, Threedimensional engineered heart tissue from neonatal rat cardiac myocytes, Biotechnol. Bioeng. 68 (2000), p. 106.

[8] Y. Miyahara, N. Nagaya, M. Kataoka, B. Yanagawa1, K. Tanaka, H. Hao, K. Ishino, H. Ishida, T. Shimizu, K. Kangawa et al., Monolayered mesenchymal stem cells repair scarred myocardium after myocardial infarction, Nature Med. 12 (2006), p. 459.

[9] K.B. Pasumarthi and L.J. Field, Cardiomyocyte cell cycle regulation, Circ. Res. 90 (2002), p. 1044; H.M. Blau, T.R. Brazelton, J.M. Weimann. The evolving concept of a stem cell: entity or function? Cell, 105 (2001), p. 829.

[10] A.M. Wobus, G. Wallukat, and J. Hescheler, Pluripotent mouse embryonic stem cells are able to differentiate into cardiomyocytes expressing chronotropic responses to adrenergic and cholinergic agents and Ca2+ channel blockers, Differentiation 48 (1991), p. 173.

[11] N.N. Malouf, W.B. Coleman, J.W. Grisham, R.A. Lininger, V.J. Madden, M. Sproul, and P.A. Anderson, Adult-derived stem cells from the liver become myocytes in the heart in vivo, Am. J. Pathol. 158 (2001), p. 1929.

[12] S. Cohen, M.C. Bano, L.G. Cima, H.R. Allcock, J.P. Vacanti, C.A. Vacanti, and R. Langer, Design of synthetic polymeric structures for cell transplantation and tissue engineering, Clin. Mater. 13 (1993), p. 3.

[13] L.G. Cima, J.P. Vacanti, C. Vacanti, D. Ingber, D. Mooney, and R. Langer, Tissue engineering by cell transplantation using degradable polymer substrates, J. Biomech. Eng. 113 (1991), p. 143.

[14] A.J. Engler, S. Sen, H.L. Sweeney, and D.E. Discher, Matrix elasticity directs stem cell lineage specification, Cell 126 (2006), p. 677.

[15] S. Hsu, S. Chang, H. Yen, S. Whu, C. Tsai, and D. Chen, Evaluation of biodegradable polyesters modified by type II collagen and Arg-Gly-Asp as tissue engineering scaffolding materials for cartilage regeneration, Art. Org. 30 (2006), p. 42.

[16] R. Fiaccavento, F. Carotenuto, M. Minieri, C. Fantini, G. Forte, A. Carbone, L. Carosella, R. Bei, L. Masuelli, C. Palumbo et al., Stem cell activation sustains hereditary hypertrophy in hamster cardiomyopathy, J. Pathol. 205 (2005), p. 397.

[17] M.M. Stevens and J.H. George, Exploring and engineering the cell surface interface, Science 310 (2005), p. 1135.

[18] W.Y. Zhou, S.H. Lee, M. Wang, W.L. Cheung, and W.Y. Ip. Selective laser sintering of porous tissue engineering scaffolds from poly(L-lactide)/carbonated hydroxyapatite nanocomposite microspheres. J. Mater. Sci.: Mater. Med., DOI 10.1007/s10856-007-3089-3. 
[19] E. Palin, H. Liu, and T.J. Webster, Mimicking the nanofeatures of bone increases bone-forming cell adhesion and proliferation, Nanotechnol. 16 (2005), p. 1828.

[20] A. Welle, M. Kröger, M. Döring, K. Niederer, E. Pindel, and I.S. Chronakis, Electrospun aliphatic polycarbonates as tailored tissue scaffold materials, Biomater. 28 (2007), p. 2211.

[21] S. Ghosh, J.C. Viana, R.L. Reis, and J.F. Mano, The double porogen approach as a new technique for the fabrication of interconnected poly (L-lactic acid) and starch based biodegradable scaffolds, J. Mater. Sci.: Mater. Med. 18 (2007), p. 185.

[22] F. Yang, X. Qu, W. Cui, J. Bei, F. Yu, S. Lu, and S. Wang, Manufacturing and morphology structure of polylactide-type microtubules orientation-structured scaffolds, Biomater. 27 (2006), p. 4923.

[23] G. Forte, F. Carotenuto, F. Pagliari, S. Pagliari, P. Cossa, R. Fiaccavento, A. Ahluwalia, G. Vozzi, B. Vinci, A. Serafino, et al., Polymeric scaffold guidance to stem cell differentiation and tissue warping, Nature Mater. (submitted Septemeber 2007).

[24] A.G. Mikos, A.J. Thorse, L.A. Czerwonka, Y. Bao, R. Langer, D.N. Winslow, and J.P. Vacanti, Polymer 35 (1994), p. 1068.

[25] T. Tanaka and D.R. Lloyd, Formation of poly (L-lactic acid) microfiltration membranes via thermally induced phase separation, J. Memb. Sci. 238 (2004), p. 65.

[26] Y.S. Nam and T.G. Park, Porous biodegradable polymeric scaffolds prepared by thermally induced phase separation, J. Biomed. Mat. Res. 47 (1999), p. 8.

[27] G. Wei and P.X. Ma, Structure and properties of nano-hydroxyapatite/polymer composite scaffolds for bone tissue engineering, Biomater. 25 (2004), p. 4749.

[28] M. Ho, P. Kuo, H. Hisieh, T. Hsien, L. Hou, J. Lai, and D. Wang, Preparation of porous scaffolds by using freeze-extraction and freeze-gelation methods, Biomater. 25 (2004), p. 129.

[29] P. Sarazin, X. Roy, and B.D. Favis, Controlled preparation and properties of porous poly(l-lactide) obtained from a co-continuous blend of two biodegradable polymers, Biomater. 25 (2004), p. 5965.

[30] L. Dan and X. Younan, Electrospinning of nanofibers: reinverting the wheel?, Adv. Mater. 16 (2004), p. 1151.

[31] G. Wei, Q. Jin, W.V. Giannobile, and P.X. Ma, Nano-fibrous scaffold for controlled delivery of recombinant human PDGF-BB, J. Controlled Release 112 (2006), p. 103.

[32] W. Sigmund, J. Yuh, H. Park, V. Maneeratana, G. Pyrgiotakis, A. Daga, J. Taylor, and J.C. Nino, Processing and structure relationships in electrospinning of ceramic fiber systems, J. Amer. Cer. Soc. 89(2) (2006), p. 395.

[33] X. Zong, H. Bien, C.-Y. Chung, L. Yin, D. Fang, B.S. Hsiao, B. Chu, and E. Entcheva, Electrospun fine-textured scaffolds for heart tissue constructs, Biomater. 26 (2005), p. 5330.

[34] E.D. Boland, G.E. Wnek, G.D. Simpson, K.J. Pawlowski, and G.L. Bowlin, Tailoring tissue engineering scaffolds using electrostatic processing techniques: a study of poly(glycolic acid) electrospinning, J. Macromol. Sci. Pure Appl. Chem. A38 (2001), p. 1231.

[35] W.-J. Li, C.T. Laurencin, E.J. Caterson, R.S. Tuan, and F.K. Ko, Electrospun nanofibrous structure: a novel scaffold for tissue engineering, J. Biomed. Mater. Res. 60 (2002), p. 613.

[36] K.E. Kadler, D.F. Holmes, J.A. Trotter, and J.A. Chapman, Collagen fibril formation, Biochem. J. 316 (1996), p. 1.

[37] Q.P. Pham, U. Sharma, and A.G. Mikos, Electrospun poly(E-caprolactone) microfiber and multilayer nanofiber/microfiber scaffolds: characterization of scaffolds and measurement of cellular infiltration, Biomacromolecules 7 (2006), p. 2796. 